\title{
DESIGN THEORY IN INFORMATION SYSTEMS
}

\author{
Shirley Gregor \\ School of Business and Information Management \\ Australian National University \\ Canberra ACT 0200 \\ shirley.gregor@anu.edu.au
}

\begin{abstract}
The aim of this paper is to explore an important category of information systems knowledge that is termed "design theory". This knowledge is distinguished as the fifth of five types of theory: (i) theory for analysing and describing, (ii) theory for understanding, (iii) theory for predicting, (iv) theory for explaining and predicting, and (v) theory for design and action. Examples of design theory in information systems are provided, with associated research methods. The limited understanding and recognition of this type of theory in information systems indicates that further debate concerning its nature and role in our discipline is needed.
\end{abstract}

\section{INTRODUCTION}

The aim of this paper is to explore the body of information systems knowledge that is referred to by terms such as “design theory” (Markus, Majchrzak, and Gasser, 2002; Walls, Widmayer, El Sawy, 1992), "design science” (March and Smith, 1995), and a "theory of artifacts" (Weber, 1987). Discussion of the nature of theory in general in information systems has been relatively limited, especially in comparison with the considerable debate that occurs over research methods and paradigms. The question of what constitutes theory appears to be a more fundamental question - one that is worthy of more attention (Gregor, 2002). The idea of design theory in particular requires critical elaboration.

Examination of what is meant by theory has occurred in other disciplines. An issue of the Academy of Management Review (1989, Vol. 14, No. 4) focussed on theory and theory development. Similarly, an issue of Administrative Science Quarterly (1995, Vol. 40, No. 3) had articles about what theory is, what theory is not and how theorizing occurs. Descriptions of theory in the social sciences can also be found in Dubin (1978), Freese (1980), Kaplan (1964), Merton (1967) and Weick (1989). More established disciplines have considerable histories of enquiry into the nature of theory. In the philosophy of science there has been discussion of scientific knowledge and the formulation of theory over a very long period (Locke, 1689; Hume, 1748; Popper, 1980).

Information Systems has a number of contributing disciplines, including mathematics, logic, philosophy, computer science, psychology, sociology, economics and management, from which theoretical bases are drawn and adapted. It is not surprising, given that many of our community have come from these different disciplines, that there are different views on what constitutes theory. The information systems discipline is now, however, recognized as a distinct discipline and we should devote some effort to considering the nature and form of theory in our own discipline

A definition of information systems suitable for our purposes is that it concerns:

the effective design, delivery, use and impact of information technology in organizations and society (Avison and Fitzgerald, 1995, p. xi).

We do not agree with Webster and Watson (2002) that information systems is another management field, like organizational behaviour. A characteristic that distinguishes information systems from these fields is that it concerns the use of artifacts in human-machine systems. Thus, we have a discipline that is at the intersection of knowledge of the properties of physical objects (machines) and knowledge of human behaviour. Information systems can be seen to have commonalities with other design disciplines such as architecture or engineering, which also concern both people and artifacts, or with other applied disciplines such as medicine, where the products of scientific knowledge (drugs, treatments) are used with people.

In this paper a wide rather than a narrow view of theory is adopted, to encompass a number of different views. Dictionary definitions show that the word "theory" can take on many meanings, including: "a coherent group of generic propositions used as principles of explanation for a class of phenomena"; "a proposed explanation whose status is still conjectural, in contrast to well-established propositions that are regarded as reporting matters of fact"; "that department of a science or art which deals with its principles or methods, as distinguished from the practice of it", "a system of rules or principles"; or "conjecture or opinion" (Macquarie Dictionary, 1981). Thus, the word theory will be used here rather broadly to encompass what might be termed elsewhere conjectures, models, frameworks, or "body of knowledge".

The remainder of this paper proceeds as follows. First, it considers briefly five different types of theory, which are labelled: (i) theory for analysing and describing, (ii) theory for understanding, (iii) theory for predicting, (iv) theory for explaining and predicting, and (v) theory for design and action. The fifth type of theory, design theory, is then explored in more detail. Illustrations of relevant work in information systems are provided, as are related research methods, and the form a contribution to knowledge could take. The paper concludes with some implications that arise from discussion of design theory. 


\section{THE NATURE OF THEORY}

In general, theory answers a human need to make sense of the world and to accumulate a body of knowledge that will aid in understanding, explaining, and predicting the things we see around us, as well as providing a basis for action in the real world. In the words of Popper (1980, p. 59):

Scientific theories are universal statements. Like all linguistic representations they are systems of signs or symbols. Theories are nets cast to catch what we call 'the world'; to rationalize, to explain and to master it. We endeavour to make the mesh ever finer and finer.

Theories are seen as uncertain and as approximate representations of reality (fallibilism):

The empirical basis of objective science has thus nothing 'absolute' about it. Science does not rest upon solid bedrock. The bold structure of its theories rises, as it were, above a swamp. It is like a building erected on piles. The piles are driven down from above into the swamp, but not down into any natural or 'given' base; and if we stop driving the piles deeper it is not because we have reached firm ground. We simply stop when we are satisfied that the piles are firm enough to carry the structure, at least for the time being (Popper, 1980, p. 111).

The ontological position adopted here recognizes theory as having an existence separate from the subjective understanding of individuals. A theory can be regarded as:

constructions about which there is relative consensus (or at least some movement towards consensus) among those competent (and in the case of more arcane material, trusted) to interpret the substance of the construction (Guba and Lincoln, 1994, p.113).

This position corresponds to ideas expressed by both Habermas and Popper. Habermas (1984) recognizes three different worlds - the objective world of actual and possible states of affairs, the subjective world of personal experiences and beliefs, and the social world of normatively regulated social relations. These three worlds are related to Popper's worlds 1, 2 and 3 (Popper, 1986). World 1 is the objective world of material things. World 2 is the subjective world of mental states, and World 3 is an objectively existing but abstract world of man-made entities - language, mathematics, knowledge, science, art, ethics and institutions. Thus, theory belongs to World 3. A computer program as an electronic artifact exists in World 1, yet the articulation of the algorithm or design principles that are represented in the program belongs to World 3.

Theory and theoretical knowledge are invented by human beings rather than being discovered. We invent concepts, models and schemes to make sense of experience and, further, we continually test and modify these constructions in the light of new experience. Theoretical terms are abstractions, human inventions that are simply convenient devices for managing and expressing the relations among observables. Concepts and ideas are invented but correspond to something in the real world.

A number of different views of theory are encompassed in this paper with a view to being inclusive. There is still a limit, however, to what is classed as theory. From the definitions above it can be seen that abstraction and generalisation about phenomenon, interactions and causation are thought to be at the core of a theory. We do not regard a collection of facts, or knowledge of an individual fact or event, as theory. "Data are not theory" (Sutton and Shaw, 1995, p. 374), though data may form the foundation for theoretical development. Thus, a description of the method used in one case for the construction of an artifact is not theory.

Views differ on the degree to which generalization or universality is required in theory. Popper (1980) provides a detailed coverage on universality and the problems associated with this concept. His view is that the natural sciences should aim at strictly universal statements and theories of natural laws (covering laws), though these laws can never be held with certainty. In the social sciences, however, it is thought unlikely that social phenomena are determined in accordance with strict laws of nature. For example, wars do not result from antecedent political tensions in the same way that earthquakes result from antecedent conditions of plate tectonics (Little, 1999). Hume (1748) illustrated this view rather well by saying, that in comparison to the universal laws, or laws of nature, knowledge of human affairs is more uncertain, so that: there are other causes, which have been found more irregular and uncertain; nor has rhubarb always proved a purge, or opium a soporific to everyone, who has taken these medicines. (p. 206). Nevertheless, we expect in the social sciences (and information systems) that theory should include generalizations to some degree.

\section{TYPES OF THEORY}

Theory can be considered on many different dimensions and can be classified in ways that differ from the categorization adopted in this paper. For example, Neuman (2000) believes theory can be categorized in terms of (i) the direction (deductive or inductive), (ii) the level of the theory, (iii) whether it is formal or substantive, (iv) the forms of explanations it employs, and (v) the overall framework of assumptions and concepts in which it is embedded.

In this paper the categorization of theory depends on the primary purpose that the theory under consideration is to serve. This purpose will in turn depend on the focal question of any research undertaken. For example, if we are interested in describing and categorizing the entities that we believe are relevant to a particular area of enquiry, development of descriptive theory is appropriate. 
The following sections describe five different types of theory that are seen as relevant to information systems. A fuller discussion of each theory type is given in Gregor (2002). These five different categories of theory are not regarded as mutually exclusive, but are inter-related.

\section{Type I: Theory for Analysing and Describing}

Descriptive theory says "what is".

Descriptive theories are the most basic type of theory. They describe or classify specific dimensions or characteristics of individuals, groups, situations, or events by summarizing the commonalities found in discrete observations. They state 'what is'. Descriptive theories are needed when nothing or very little is known about the phenomenon in question. (Fawcett and Downs, 1986, p. 4)

There are two categories of descriptive theory - naming and classification (Stevens, 1984). A naming theory is a description of the dimensions or characteristics of some phenomenon. A classification theory is more elaborate in that it states that the dimensions or characteristics of a given phenomena are structurally interrelated. The dimensions may be mutually exclusive, overlapping, hierarchical, or sequential. Classification theories are frequently referred to as typologies, taxonomies or frameworks.

Research approaches for building descriptive theory include analysis of existing evidence or data, philosophical and historic enquiry and empirical observation.

\section{Type II: Theory for Understanding}

This type of theory explains "how" and "why" something occurred. It is not formulated in such a way, however, that predictions about the future are made so that they can be tested.

At least two types of work may be distinguished here. In the first, theory is used as a "sensitising device" to view the world in a certain way (Klein and Myers, 1999, p. 75). Similarly, DiMaggio (1995, p. 391) describes "theory as enlightenment" where theory serves as:

A device of sudden enlightenment. From this perspective theory is complex, defamilarizing, rich in paradox. Theorists enlighten not through conceptual clarity... but by startling the reader into satori. The point of theory, in this view, is not to generalize, because many generalizations are widely known and rather dull. Instead, theory is a 'surprise machine' .., a set of categories and domain assumptions aimed at clearing away conventional notions to make room for artful and exciting insights.

Examples of theory used in this way in information systems are structuration theory and actor-network theory (Klein and Myers, 1999). Structuration theory is a meta-theoretical social framework developed by Giddens (1984) that argues that action and structure operate as a duality, simultaneously affecting each other. Orlikowski (1992) developed a structurational model of technology which made the claim that technology is both constituted by human agency and constitutes human practice.

In a second type of theory for understanding, "conjectures" are drawn from a study of how and why things happened in some particular real world situation. These conjectures could form the basis of subsequent theory development, or be used to inform practice.

Research approaches that can be used to develop this type of theory include case studies (Yin, 1994), surveys, ethnographic, phenomenological and hermeneutic approaches (Denzin and Lincoln, 1994), and interpretive field studies (Klein and Myers, 1999).

\section{Type III: Theory for Predicting}

Theories aiming at prediction say "what will be". These theories are able to predict outcomes from a set of explanatory factors, without necessarily understanding or explaining the causal connections between the dependent and independent variables.

Associated research approaches include statistical techniques such as correlational or regression analysis. Correlational work can be longitudinal, that is, we can show how $\mathrm{Y}$ varies with a number of independent variables $\left(\mathrm{X}_{1}, \mathrm{X}_{2}, \ldots\right)$ over a time period. Correlation studies can also be multi-directional, that is we can say larger values of $\mathrm{X}$ are related to larger values of $\mathrm{Y}$, and also larger values of $\mathrm{Y}$ are related to larger values of $\mathrm{X}$ (as in height and weight of the population).

\section{Type IV: Theory for Explaining and Predicting}

This type of theory says "what is”, "how”, "why” and "what will be”. To many it is the real view of theory (the traditional view).

A theory is a set of interrelated constructs (concepts), definitions, and propositions that presents a systematic view of phenomena by specifying relations among variables, with the purpose of explaining and predicting the phenomena. (Kerlinger, 1973, p.9) 
This theory type implies both prediction and understanding of underlying causes, as well as good description of theoretical constructs. Authorities can be found for the dimensions and specification of theories of this type (for example, Dubin, 1978).

In the social sciences the predictions made are not expected to take the form of universal or covering laws, but rather to be probabilistic-type propositions (Little, 1999, p. 705).

Almost all research methods can be used to investigate aspects of theory of this type, including case studies, surveys, experiments, statistical analysis, field studies, and also interpretive methods if they are used to build theory with predictive power. The grounded theory approach (Strauss and Corbin, 1994a, 1994b) can be used to develop theory, which is at some point capable of prediction, and thus being tested.

\section{Type V: Theory for Design and Action}

This type of theory has two aspects. First, it can concern the methodologies and tools used in the development of information systems. Second, it can be about "design principles", which are design decisions and design knowledge that are intended to be manifested or encapsulated in an artifact, method, process or system. In both cases it must be possible to articulate the principles instantiated in the method, tool, process, or design. It is this articulation, whether in natural language, diagrams or similar, that constitutes the design theory.

This fifth type of theory is discussed in greater detail in the section that follows.

\section{DESIGN THEORY ELABORATED}

Design theory is a normative or prescriptive type of theory - it gives guidelines or principles that can be followed in practice. What discussion exists of this type of theory in the information systems literature is scattered and appears under different labels. Associated research has been referred to as engineering type research (Cecez-Kecmanovic 1994), as a constructive type of research (Iivari, Hirschheim and Klein 1998), as prototyping (Baskerville and Wood-Harper, 1998), and a systems development approach (Lau, 1997; Burstein and Gregor, 1999). March and Smith (1995) use the term "design science". The term "design theory" is used here, following Walls et al. (1992)

There appears to be reluctance by some in the information systems discipline to accept the importance of this type of knowledge. For example, Galliers (1992) excluded engineering-type research as a research methodology. It is clear, however, that it occupies an important place in information systems. A review by Morrison and George (1995) of three leading management information systems journals showed that softwareengineering related research represented about $45 \%$ of the information systems articles found in the six-year period from 1986 to 1991. Iivari et al. (1998) also argue for the particular importance of these types of methods for applied disciplines, such as information systems and computer science.

Design theory concerns both how to undertake the building of an artifact (development process knowledge) and what the artifact should look like when built (design principles). These aspects or design theory are intertwined. Artifacts based on information technology are not static but evolve - through human actions and from new technological development. In addition, the nature of the artifact is likely to reflect the tools and methodologies used in its construction. Some design theory links particular types of artifacts to particular methods for their construction. For example, Truex et al. (1999) make the claim that organizations that are not stable, but continuously adapting to their environment, need system development methods that assume that systems should be under constant development, can never be fully specified, and are subject to constant adjustment and adaptation.

There are a number of views of design theory, both in information systems and in related disciplines. Cook and Campbell (1979. p. 28) identified the requirement for knowledge of this type in the social sciences, but used the term "recipe":

Knowledge of causal manipulanda, even the tentative, partial and probabilistic knowledge of which we are capable, can help improve social life. What policy makers and individual citizens seem to want from science are recipes that can be followed and that usually lead to desired positive effects, even if understanding of the micromediational processes is only partial and the positive effects are not invariably brought about.

In 1987 Weber indicated the difficulties with some instances of design work. He saw the "lure of design and construction" as one of three factors inhibiting the progress of information systems as a discipline.

The conundrum posed by design research for progress in a discipline emerges clearly when a paper describing such research must be evaluated for publication in a learned journal. What are the quality standards the reviewer must apply to decide upon its acceptability? Typically the paper contains no theory, no hypotheses, no experimental design, and no data analysis. Traditional evaluation criteria cannot be used. The paper's contribution inevitably requires an inherently subjective evaluation (p. 9).

Landauer (1987), points out problems with the argument that systems design can be guided by an underlying design theory: 
Previous research findings and theories are likely, at best, to be relevant only to a small portion of the total situation. It means that testing the effectiveness of one total system against that of another is likely to yield information of extremely limited generality (p. 157).

Walls et al. (1992) considered that an information systems design theory had two distinctive characteristics: a theoretical base and explicit guidance for practitioners. Design theory should have three interrelated components: a set of user requirements, a set of system features (or principles for selecting system features), and a set of principles deemed effective for guiding the process of development. The theory underlying an information systems design theory (referred to as "kernel theory") could be an academic theory (e.g cognitive psychology) or a practitioner theory-in-use (Sarker and Lee, 2002). These authors argued that the value of an IS design theory lay in the diminution of developers' uncertainty through a reduction of the range of allowable system features and development activities to a more manageable set, thereby increasing the likelihood of success.

In the field of management accounting, Kasanen, Lukka and Siitonen (1993) argued for the usefulness of a "constructive approach" to research, which promoted managerial problem solving through the construction of models, diagrams, plans, organizations and so on. These authors recognize that in their field such research suffered from a perception that it is "non-scientific" and is liable to be confused with consulting.

March and Smith (1995) discussed "design science” in terms of the development of understanding of the natural laws governing information technology systems and the natural laws governing the environments in which they operate. They considered that two groups of activities are needed for design science. The first includes the research activities of: build, evaluate, theorize and justify. The second includes the outputs of representational constructs, models, methods, and instantiations.

In the field of software engineering, Glass (1996) discussed the close relationship between theory and practice, showing how practice can lead to theory, and theory to practice. This relationship is illustrated in aerodynamics, where the invention of the airfoil preceded and motivated the science of aerodynamics. Glass points out that practice may lead to theory -the best methodologies and representations for software design in the world will not necessarily lead us to superior designs. There is something else in the act of design - the art, skill and experience of the designer.

Limited discussion of research approaches for design theory can be found. Exceptions are Burstein and Gregor (1999), March and Smith (1995), Nunamaker, Chen and Purdin (1990-91), Nunamaker and Chen (1990). Action research is seen as particularly appropriate (Baskerville and Wood-Harper, 1996). Lau (1997) reviewed the use of action research in information systems studies over a twenty-five year period. Eleven of the thirty articles reviewed were categorized as "systems development", covering the areas of analysis, design, development and implementation of information systems and decision support systems.

The above discussion shows a range of thoughts on design theory in Information System and allied fields. It can been seen that to date a coherent unified view has not emerged, and that there is some unease as to whether design theory is "scientific" and properly distinguishable from consulting.

\section{TOWARDS A BETTER UNDERSTANDING OF DESIGN THEORY}

The view adopted here is that design theory is, in essence, a variation of traditional theory that both explains and predicts. In this view design theory should have well-defined constructs, definitions and propositions that both explain and predict phenomena. The difference is that this type of theory has an additional role in that it is normative or prescriptive. The propositions go a step further and say "how something should be done".

The paper by Markus et al (2002) is a good example of a theory of this type. It gives explicit design and development principles for the class of application systems that supports emergent knowledge processes. An example advanced of a design principle is: "design for implicit guidance through a dialectical development process". This principle (proposition) has a predictive element and can be phrased in a fashion similar to propositions in traditional theory. That is, this principle implies that "A dialectical development process is better (in some sense) than alternative development processes for the class of systems that support emergent knowledge processes". Other researchers can test this proposition with other systems of this nature. In their own research the authors show that an alternative development process "of explicit guidance" was faulty. The design theory proposed consists of general principles to solve a class of business problems, rather than a unique set of system features to solve a unique business problem. The abstraction and generalization that occurred here distinguishes the study from what would occur in consulting.

Design theory can be informed by all the other types of theory. A general, formalized methodology can build on particular idiographic studies of what has worked in practice, on predictive relationships that are known but not fully understood and on traditional theories such as those relating to data representation or human behaviour. Figure 1 illustrates these relationships. 


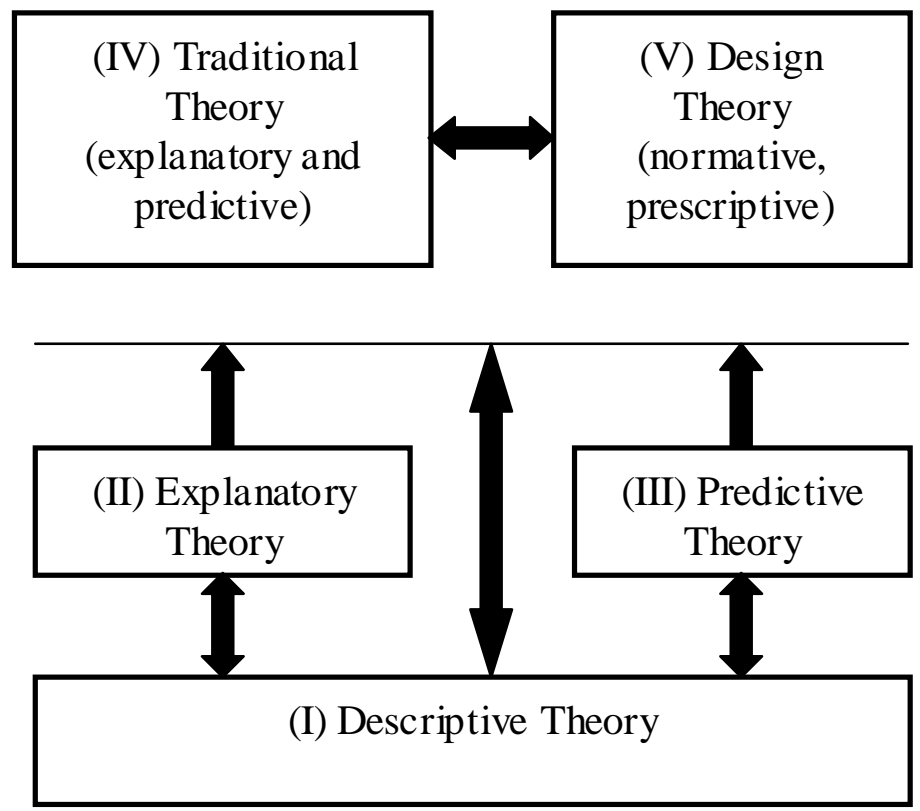

Figure 1: Interelationships among theory types

The interrelationships between the theory types can be bi-directional. Work on design theory could lead to advances in other types of theory. For example, principles of interface design that are tested in software trials could lead to improvement in underlying theories of cognitive psychology (of the traditional type). Similarly, practical implementations of methods may lead to refinement of frameworks, taxonomies or construct definition.

An apparent divergence in opinions can be detected in the views of design theory. One view places emphasis on the development of deep theories of information systems of the traditional type (Type IV), which can then inform design practice. For example, Weber (1987), saw a solution to the dilemma posed by design and construction work if:

Researchers show how their designs are based in some theory of information systems. The theory can be used to predict the likely success or failure of a design, and these predictions can be tested empirically.

Traditional evaluation criteria can then be applied (p. 9).

Weber's work is clearly motivated by this aim. He provides what could be termed a "Theory of Representation in information systems" using a formalization of a system based on the ontology of Mario Bunge (Weber, 1997). This theory has implications for design practice in that it allows predictions about the strengths and weaknesses of various forms of information system representations (grammars) that can be tested in empirical work. Cumulative work on this theory has continued with studies aimed at testing propositions derived from the theory (for example, Bodart et al., 2001).

March and Smith (1995) discuss "design science", but do not regard theory as a product of design science: "Rather than posing theories, design scientists strive to create models, methods and implementations that are innovative and valuable.” (p. 254). Markus et al. (2002), following Walls et al. (1992) recognize design "theory", but believe that "IS design theory is not a radical departure from established IS practice and theorizing” (p. 181).

We argue for an alternate view that recognizes design theory (type V) as special case of traditional theory (Type IV), but distinguished from it as a separate category, so that its particular characteristics can be discussed. In much work of the traditional-theory type the primary focus is an integrated body of knowledge - the design implications are secondary. In contrast, with design theory the primary focus is the general design principles that inform practice, as Cook and Campbell (1979) noted with their idea of "recipes". The knowledge needs to be stated in such a way that it provides guidance in practice for the design, development and use of information systems.

Design theory can arise from a situation in which imagination, art, or a designer's insights result in a new way of solving problems being "discovered". This discovery can be instantiated in an artifact, providing "proof-ofconcept”. The new design theory could be based on existing theories of Type IV - what Walls et al. (1992) 
term "kernel” theory" - that are combined together or interpreted in new or novel ways. This situation is similar to "theory-building" with traditional theory, and is congruent with views in the philosophy of science. Popper (1980) says that the act of conceiving or inventing a theory is a matter of psychology and not the province of science.

What constitutes a contribution to knowledge with design-type research? Some criteria adapted from March and Smith (1995) are:

- In the theory-building phase, the value or utility to a community of users is important, especially with the first artifact of any type:

Building the first of any set of constructs, model, method or instantiation is deemed to be research, provided the artifact has utility for an important task. The research contribution lies in the novelty of the artifact and in the persuasiveness of the claims that it is effective. (p. 260)

- With research that builds subsequent constructs, models, methods and instantiations, judgement is based on 'significant improvement"; whether the artifact offers, for example, improvements such as better performance, efficiency, understandability or ease-of-use.

- Instantiations that apply known constructs, methods and principles, to novel tasks may be of little significance. The prime concern is with the uncertainty of the success of the artifact - for example, applying expert system technology to build a system in a well-structured domain is likely to be of little significance when there is little uncertainty about its chance of success.

- In theory-testing, the evaluation of artefacts is worthwhile design theory research. Different artefacts can be evaluated with respect to different metrics. For example, evaluation of constructs (such as data modelling formalisms) tends to involve completeness, simplicity, elegance, understandability and ease of use. Models (such as database design models) are evaluated in respect of their fidelity with realworld phenomena, completeness, level of detail, robustness, internal consistency and usefulness in practice. Evaluation of methods considers operationability (the capacity of an algorithm to perform a task or of humans to effectively use the method), efficiency, generality, and ease of use. For example, systems development methods or tools can be evaluated with respect to the quality of results obtained by analysts applying the methods or tools.

In addition, it is assumed that the general design principles represented in the artifact are articulated clearly so that they can be followed and tested by others. Criteria for software development (design) research are discussed further in Burstein and Gregor (1999).

The study by Markus et al (2002) provides a good example of design theory. The claim is made, and justified, that there was no suitable existing design theory for a particular class of systems. Thus, the claim is made that the design principles proposed are new and novel. Design principles were drawn from the development of a tool that was shown to be successful in two pilot studies (though little detail of evaluation or use is given). The design theory (principles) is well articulated and suggestions are given as to how this theory can be tested in further work.

\section{DISCUSSION AND CONCLUSIONS}

This paper has distinguished five different types of theory important for the discipline of information systems: (i) theory for analysing and describing, (ii) theory for understanding, (iii) theory for predicting, (iv) theory for explaining and predicting, and (v) theory for design and action.

The fifth category of design theory was discussed in detail. Prior discussion of this type of theory in information systems is relatively sparse and what work does exist is not entirely congruent. We argue that design theory should be distinguished from other types of theory to allow its nature to be examined in some detail. Design theory is seen as a special case of traditional theory that allows for both explanation and prediction and testing of propositions. The distinctive feature of design theory is that it is normative and gives guidance (design principles) for action in the real world. These design principles relate to artifacts that include system or subsystem models, artifact features and development methodologies and tools.

The importance of design theory in information systems should be recognized. We are essentially an applied discipline, one in which our work should provide guidance to people who have to take action in the world. Thus, a critical examination of what design theory entails is valuable. It would be advantageous if we could come to some common understanding of the form that knowledge claims in this theory can take, and the means by which such knowledge claims are developed and tested. 


\section{REFERENCES}

Avison, D. \& Fitzgerald, G. (1995) Information Systems Development: Methodologies, Techniques and Tools, $2^{\text {nd }}$ ed., McGraw-Hill, London.

Baskerville, R. \& Wood-Harper, A. T. (1998) "Diversity in Information Systems Action Research Methods", European Journal of information systems, 7, 90-107.

Bodart, F., Patel, A., Sim, M. \& Weber, R. (2001) "Should Optional Properties be used in Conceptual Modelling? A Theory and Three Empirical Tests, Information Systems Research, 12(4), pp 384-405.

Burstein, F. \& Gregor, S. (1999) “The Systems Development or Engineering Approach to Research in Information Systems: An Action Research Perspective” in B. Hope \& P. Yoong (eds) Proceedings of the $10^{\text {th }}$ Australasian Conference on Information Systems, Victoria University of Wellington, New Zealand, pp 122-134.

Cecez-Kecmanovic, D. (1994) “Engineering Type Information Systems Research: A Discussion on its Position and Quality”, Proceedings of the 5th Australian Information Systems Conference, Caulfield, Vic., Monash Department of information systems, pp 767-770.

Cook, T. D. \& Campbell, D. T. (1979) Quasi-Experimentation Design and Analysis Issues for Field Setting, Boston, MAL Houghton Mifflin.

Denzin, N. K., \& Lincoln, Y. S. (eds.), (1994) Handbook of Qualitative Research, Thousand Oaks, CA: Sage.

DiMaggio, P. J. (1995) “Comments on 'What Theory is Not”, Administrative Sciences Quarterly, 40(3), pp 391-397.

Dubin, R. (1978) Theory building. (Rev. ed.). London: Free Press.

Fawcett, J. \& Downs, F.S. (1986). The Relationship of Theory and Research, Norwalk, CT: AppletonCentury-Crofts.

Freese, L. (1980) “Formal Theorizing”, Annual Review of Sociology, 6, pp 187-212, Palo Alto, CA.

Galliers, R. (1992) “Choosing Information Systems Research Approaches” in Galliers, R. (ed.) Information Systems Research: Issues, Methods and Practical Guidelines, Blackwell Scientific Publications, Oxford, pp 144-162.

Giddens, A. (1984) The Constitution of Society. Cambridge: Polity Press.

Glass, R. L. (1996) “The Relationship Between Theory and Practice in Software Engineering”, Communications of the ACM, 39(11), pp 11-13.

Gregor, S. (2002) “A Theory of Theories in Information Systems” in Gregor, S. \& Hart, D. (eds.), Information Systems Foundations: Building the Theoretical Base, Australian National University, Canberra, pp 1-20.

Guba, E. G. \& Lincoln, Y. (1994) “Competing Paradigms in Qualitative Research” in Denzin, N. K. \&. Lincoln, Y. S. (eds.), Handbook of Qualitative Research, Thousand Oaks, CA: Sage, pp 105-117.

Habermas, J. (1984) Theory of Communicative Action., Vol 1: Reason and the Rationalization of Society. Heinemann, London, U.K.

Hume, D. (1748) “An Enquiry Concerning Human Understanding”, Reprinted in Perry J. \& Bratman, M. (eds.), Introduction to Philosophy Classical and Contemporary Readings ( ${ }^{\text {rd }}$ ed.). New York: Oxford University Press , 1999.

Iivari, J., Hirschheim, R. \& Klein, H. K. (1998) “A Paradigmatic Analysis Contrasting Information Systems Development Approaches and Methodologies”, Information Systems Research, June , pp 164 - 193.

Kaplan, A. (1964) The Conduct of Enquiry. New York: Harper Row.

Kasanen, E., Lukka, K., \& Siitonen, A. (1993) “The Constructive Approach in Management Accounting Research”, Journal of Management Accounting Research, 5, pp 243-264.

Kerlinger, F.N. (1973) Foundations of Behavioural Research, ( $2^{\text {nd }}$ ed.) New York: Holt, Rinehart and Winston.

Klein, H. \& Myers, M. (1999) “A Set of Principles for Conducting and Evaluating Interpretive Field Studies”. MIS Quarterly, 23(1), pp 67-93.

Landauer, T. K. (1987) “Relations Between Cognitive Psychology and Computer System Design” in Carroll, J. M. (ed.), Interfacing Thought, MIT Press.

Lau, F. (1997) “A Review on the Use Of Action Research in Information Systems Studies” in Liebenau, L. A. \& DeGross, J. (eds.), Information Systems and Qualitative Research, Chapman \& Hall, London, pp 3168.

Little, D.E. (1999) "Philosophy of the Social Sciences” in Audi, R. (ed.) The Cambridge Dictionary of Philosophy ( $2^{\text {nd }}$ ed.) Cambridge, UK: Cambridge University Press, pp 704-706.

Locke, J. (1689) “Essay Concerning Human Understanding” Reprinted in Perry, J. \& Bratman, M. (eds.) Introduction to Philosophy Classical and Contemporary Readings ( ${ }^{\text {rd }}$ ed.) New York: Oxford University Press, 1999.

March, S.T. \& Smith, G.F. (1995) “Design and Natural Science Research on Information Technology”, Decision Support Systems, 15, pp 251-266.

Markus, L., Majchrzak, A., \& Gasser, L. (2002) “A Design Theory for Systems that Support Emergent Knowledge Processes”, MIS Quarterly, 26(3), pp 179-212.

Merton, R.K. (1967) Theoretical Sociology. New York: Free Press. 
Morrison, J. \& George, J.F. (1995) "Exploring the Software Engineering Component in MIS Research", Communications of the ACM, 38,7, pp 80-91.

Neuman, W. L. (2000) Social Research Methods (4 ${ }^{\text {th }}$ edn.) Boston: Allyn \& Bacon.

Nunamaker, J., Chen, M. \& Purdin, T. (1990-91) “Systems Development in Information Systems Research”, Journal of Management Information Systems, 7 (3), pp 89-106.

Nunamaker, J.F. \& Chen, M. (1990) “Systems Development in Information Systems Research”, IEEE, pp 631639.

Orlikowski. W. (1992) “The Duality of Technology: Rethinking the Concept of Technology in Organizations”, Organization Science, 3(3), pp 398-427.

Popper, K. (1959) The Logic of Scientific Discovery, London: Unwin Hyman.

Popper, K. (1986). Unended quest an intellectual autobiography, Glasgow: Fontana.

Sarker, S., \& Lee, A.S. (2002) "Using a Positivist Case Research Methodology to Test Three Competing Theories-InUse of Business Process Reengineering”, Journal of the AIS, 2(7) (online).

Stevens, B.J. (1984) Nursing theory. Analysis, application, evaluation, ( ${ }^{\text {nd }}$ ed.). Boston: Little, Brown.

Strauss, A., \& Corbin, A. (1994a) Basics of Qualitative Research: Grounded Theory Procedures And Techniques, Newbury Park, CA: Sage.

Strauss, A., \& Corbin, A. (1994b) “Grounded Theory Methodology: An Overview” in Denzin, N.K., \& Lincoln, Y. S. (eds.), Handbook of Qualitative Research, Thousand Oaks, CA: Sage, pp 273-285

Sutton, R.I \& Staw, B.M. (1995) “What Theory is Not”, Administrative Sciences Quarterly, 40(3), pp 371384.

The Macquarie Dictionary (1981) Macquarie Library, McMahons Point, NSW, Australia.

Truex, D. P., Baskerville, R., \& Klein, H. (1999) “Growing Systems in Emergent Organizations”, Communications of the ACM, 42(8), pp 117-123.

Walls, J. G., Widmeyer, G. R., \& El Sawy, O. A. (1992) "Building an Information System Design Theory for Vigilant EIS”, Information Systems Research, 3(1), pp 36-59.

Weber, R. (1987) “Toward a Theory of Artifacts: A Paradigmatic Base for Information Systems Research”, Journal of Information Systems, Spring, pp 3-19.

Weber, R. (1997) Ontological Foundations of Information Systems, Melbourne, Vic.: Coopers \& Lybrand.

Webster, J. \& Watson, R. T. (2002) “Analysing the Past to Prepare for the Future: Writing a Literature Review”, MIS Quarterly, 26(2), xiii-xxiii.

Weick, K. E. (1989) “Theory Construction as Disciplined Imagination”, Academy of Management Review, 14(4), pp 516-531.

Yin, R. K. (1994) Case Study Research Design and Methods ( $2^{\text {nd }}$ ed.), Thousand Oaks, Ca: Sage. 